\title{
Visual perception of markings
}

\author{
WILLIAM H. ITTELSON \\ University of Arizona, Tucson, Arizona
}

\begin{abstract}
Markings, such as designs, writings, diagrams, and depictions, are expressive and communicative human artifacts. The conventional assumption that findings from the study of the visual perception of markings - in particular, of pictures - can be generalized to real-world perception is examined and found to be false. The processes involved in the visual perception of the world and in the visual perception of markings differ in significant ways, and generalizations from one to the other must be undertaken with caution. The visual perception of markings is an identifiable and separate area of study. Implications for a general theory of the perception of markings are examined, and the perception of markings is contrasted with real-world perception.
\end{abstract}

A large part of contemporary human visual activity is devoted to the perception of patterns on surfaces. As I sit at my breakfast table, my morning newspaper has printing on it; it has a graph telling me how the national budget will be spent, a map trying to tell me something about the weather, a table of baseball statistics, an engineering drawing with which I can build a garden chair, photographs of distant places and people, a caricature expressing what the editor thinks of a political figure, and an artist's rendition of what the city will look like 20 years from now. My plate has a decorative frieze running around its rim. The tablecloth is decorated with stylized flowers. The floor has an elaborate tiling pattern. On the wall in front of me hangs an abstract painting. Next to that, there is a calendar. Above the calendar is a clock. All this and more, and I haven't even turned on the TV or the computer, which can present it all to me on a single surface at my command. All of these are examples of markings. It will be the purpose of this paper to argue that (1) markings constitute a separate, identifiable, and unitary class of visual stimuli, (2) markings are processed differently from the manner in which other types of visual inputs are processed, and (3) the study of the perception of markings leads to conclusions with important theoretical, methodological, and applied implications.

\section{WHAT ARE MARKINGS?}

Markings are a subset of all two-dimensional patterns on the surfaces of three-dimensional objects. They are characterized by two properties: (1) markings appear on a surface, but they do not refer to the surface-their informa-

The author thanks Felice Bedford and Paul Bloom for their valuable and insightful criticisms of earlier drafts of this paper, and Mary Peterson for many helpful discussions. The author is also grateful to James Cutting, Michael Kubovy, Claudia Carello, and two anonymous reviewers for their valuable assistance and support. Correspondence should be addressed to the author at the Department of Psychology, University of Arizona, Tucson, AZ 85721 (e-mail: ittelson@ccit. arizona.edu). tional content is "decoupled" from its real-world sourceand (2) markings do not occur "naturally"- they are intentional, expressive, and communicative human artifacts.

\section{Markings Are on the Surface But Not of the Surface}

Markings owe their existence to the capacity of the human visual system to receive a certain class of input from the external world and decouple the informational content of the input from its real-world source. This remarkable ability is so much a part of our everyday experience that it easily escapes notice. But consider the generally accepted evolutionary and adaptive role of vision: to provide the organism with reasonably accurate information about the ongoing state of relevant aspects of the immediately present world. That is what visual systems are good for, and they are immensely good at it. Vast numbers of organisms, including humans, depend for their existence on this capacity of their nervous systems. But the human visual system can also do something dramatically different. It can categorize some visual information as having nothing to do with the state of the immediately present world from which it comes. Decoupling of the information from its source is the necessary defining condition for both the production and the perception of markings. The study of markings starts with this fundamental difference between the visual perception of markings and the generally recognized adaptive function of the visual systems of organisms.

The terminology used here needs to be made explicit. A marking is a pattern that appears on a surface. The term marking always entails that (1) there is a surface and (2) the informational content of the marking does not refer to the surface. While the surface can exist without the marking, the marking cannot exist without a surface. If I spray-paint my name on the side of a building, I am defacing the surface; if I paint a mustache on the Mona Lisa, I am defacing the Mona Lisa, not the surface. All this is in accord with everyday usage. For example, the weather map in my newspaper is, loosely speaking, about the weather. The surface of the newspaper has nothing to 
do with the weather but provides information about the kind of paper being used. Put them together and I have a weather map on the surface of a newspaper, typically referred to simply as "the weather map." I can transfer the map to my computer screen, giving me the same marking on a different surface. The information in the marking, weather, is decoupled from the surface, although the marking always carries a surface along with it.

An apparent contradiction arises here. Surely, I can tell by looking at the marking if it is on the surface of a newspaper or a computer screen, or if that surface is curved or flat, how it is oriented in space, if and how it is textured, and more. The marking, it would seem, can and does provide information about the surface on which it appears. Of course, this is true. Any specific instance of the weather map can be on a newspaper or on a computer screen; it cannot be on both. The marking is not physically detached from the surface; considered as a particular pattern on a particular surface, it necessarily tells us something about the surface. But considered as an instance of the general class of markings, it is not about the real-world surfaces on which it appears. The information in the marking is precisely that which is invariant over changes in the surface on which the marking appears, and the capacity to perceive that information without reference to the real-world situation in which it is found makes the existence of markings possible.

What, then, is the status of markings as part of the physical world? We commonly refer to markings as being two-dimensional, but there are no two-dimensional entities in the real world. The environment and all the objects in it are, in human terms and by human scale, three-dimensional. Some (leaves, paper) are exceedingly thin; some are both thin and transparent. But no matter how thin one slices it, the resulting lamina remains threedimensional. This three-dimensional world with threedimensional objects is the world in which the human visual system evolved. The concept of two-dimensionality is a human construct. Nevertheless, two-dimensional patterns on surfaces are all around us, and it is to a particular class of those patterns that this paper is addressed. Extending conclusions about markings to three-dimensional objects is an interesting and important project, but it will not be undertaken here. Wherever the term marking is used, it refers exclusively to two-dimensional patterns.

Markings, of course, are real; they do exist in the world. They are created and destroyed through physical actions, and they are presented to our senses by patterns of light. But contrast a marking with the physical object on the surface of which it appears. That object is certainly part of the real world. It can be touched, smelled, put up, taken down, thrown across the room, and acted on as any realworld object. But what can we do with the marking itself? We can contemplate it, think about it, ask questions about it, have feelings about it; or we can change it, for better or worse. But that is all. We cannot walk on it, climb it, sit on it, fight it, hunt it, play with it, eat it, communicate with it, have sex with it. One would be tempted to say that markings are absolutely useless, if the capac- ity to create and utilize markings did not play so obviously important a part in human life. Markings are psychologically important precisely because they provide information about something other than the real-world situations in which they are encountered.

\section{Markings Are Human Artifacts}

In nature, many patterns are found on the surfaces of objects, but these are not markings; they are part of the objects and surfaces themselves and provide information about those objects and surfaces. The zebra has its stripes, and the leopard has its spots. The stripes say, "zebra," and the spots say, "leopard." More generally, nature produces a wide variety of fascinating patterns (Stevens, 1974; Weyl, 1952); they can have great explanatory power, telling us much about the structure and history of the objects and surfaces on which they appear. Naturally occurring objects and surfaces are often defined, identified, and understood by the patterns and textures of their surfaces. Many of those patterns are also of great beauty and can be perceived, experienced, and appreciated purely as designs. They are thus converted into markings by the intentions of the human observer, a process much debated with reference to "found art" (Levinson, 1993). Pictures and diagrams of naturally occurring patterns are certainly markings, but they are not to be confused with the actual patterns themselves.

Are we justified in the claim that producing and perceiving markings are limited to humans? Markings come in a number of varieties, of which only pictures-a small, though important, subset-have received significant comparative research. There is general agreement in the literature that animals do not produce pictures. Whether animals can perceive markings-and in particular, pictures-produced by humans is less clear (Cabe, 1980). A comprehensive up-to-date review of this work is needed but is beyond the scope of this paper and the expertise of the author. But a note of caution can be offered. Much of the animal picture perception literature is devoted to showing that animals can learn to discriminate among pictures and can transfer these discriminations to new pictures (Herrnstein \& Loveland, 1964; Wasserman, 1993, 1995). But the perception of markings is defined by the decoupling of the information provided by the marking from the real-world source of the marking. Discrimination among pictures does not address this issue. The animal must, at a minimum, show transfer from pictures of the real world to the real world, transfer from the real world to pictures, and discrimination between the two. There is little evidence that animals, except perhaps some primates, have this capacity.

Certainly, the production and, probably, the perception of markings are limited to humans. However, this general conclusion does not preclude the possibility that some animals may exhibit some form of picture perception. The study of the capacity of animals to perceive pictures and markings in general, like the study of tool use in animals and the study of animal communication, can be expected to reveal the rudimentary precursors that 
argue for evolutionary continuity and, at the same time, dramatize the qualitative and quantitative differences between human and animal performance. But whether any animals perceive pictures, as defined above, spontaneously or can be trained to do so remains in the present state of our knowledge highly problematic.

In contrast, the capacity to produce and perceive pictures-and markings in general-seems to be built into the human nervous system. Children follow a fairly definite developmental sequence in producing (Fein, 1993; Tversky, 1995) and perceiving (DeLoache \& Burns, 1994; Nye, Thomas, \& Robinson, 1995) pictures. Infants recognize objects in pictures and can discriminate picture from object. Understanding the representational function of pictures, decoupling the information from its source, comes later, followed by the recognition that pictures are carriers of intentional relations. The exact nature of this sequence and the ages at which it becomes manifest are probably not as yet completely known. But it is clear that, at some point — probably about 8 or 9 yearsthe child approximates the adult understanding "that pictures are vehicles of representation, mediating communication from one mind (artist) to another (beholder) about a state of affairs real or imaginable" (Freeman, 1995, p. 140).

In summary, real-world objects and environments are universal in space and time: they are always and everywhere to be found. One cannot even imagine a world in which there is no environment or are no objects. Environments and objects, at least in evolutionary time, have always existed. Markings are different. They are not produced qua markings in "nature"; they appear as human products. It is easy to imagine a world without markings; indeed, in evolutionary terms, humans and all other organisms evolved in just such a world. The appearance of markings is coincident with the appearance of modern man. Humans seem uniquely to possess the capacity to create and utilize markings.

Markings, however, are strange creatures. Considered as physical stimuli, they are independent of the real-world situation in which they are encountered and, indeed, even of the medium through which they are presented. Considered as psychological input, they provide no immediate real-world information. In short, markings differ from real-world visual stimuli in their status as part of the world, in what they provide information about, and in how they are processed psychologically. These issues will be discussed in the final section of this paper, but, first, we will try to put some order into the many varieties of markings and then look further into one particular case: picture perception.

\section{VARIETIES OF MARKINGS}

Developing a taxonomy of markings presents special difficulties since it cannot be based on differences in their physical descriptions. Consider an example suggested by Arnheim (1971): "A triangle may be a sign of danger or a picture of a mountain or a symbol of hierarchy" (p. 136). We add that it may also be a decorative motif, a graph of data, an element of a road map, a letter of an alphabet, and many others. Note first that the surface on which the triangle appears is irrelevant. These cases cannot be differentiated by their patterns. There is only one triangle: it fits all cases. I now point to our triangle and say, "That is a letter in the Greek alphabetspecifically, a delta." I point to it again and say, "That is a mountain." These are perfectly acceptable statements, and either one could be correct. But how did we arrive at such disparate ends while starting from the same place? We can account for this only in terms of our ability to decouple the information "triangle" from the physical source that gave rise to it (e.g., computer screen). The triangle does not provide information about the computer screen. This decoupling, in turn, makes possible a large number of outcomes, among which are deltas and mountains. The same pattern can be perceived differently; different patterns can be perceived as the same. Markings cannot be categorized or differentiated by their patterns or by their referents. Equally irrelevant are the surfaces on which markings appear and the methods used to produce a marking on a surface, whether light or shadow, pen or pencil, engraving or xeroxing. Neither patterns, referents, surfaces, nor mechanics of production suffice to categorize markings.

The characteristics by which markings might be classified emerge in terms of the role they play in the human perceptual, cognitive, and affective system. If we look for guidance at the various roles played by the triangle in the above example, we find that they can be differentiated in terms of the intentions behind their production and use. Referring again to our triangle, four general intentional categories emerge as a useful taxonomy: $d e-$ signs, writings, diagrams, and depictions. This is not a list of rigorously defined, mutually exclusive categories but rather is a first attempt to put some order into an unsystematized field and to indicate the extent of the domain that can properly and profitably be studied under the general rubric of markings. The approach taken brings these diverse topics together as aspects of a common psychological process.

Designs are intended primarily to be decorative; their role is first and foremost affective and aesthetic. Designs might be considered a superordinate category: all markings, whatever other functions they may serve, can also be perceived as designs. Nevertheless, there is a distinct class of markings whose primary role is as designs. They may be abstract geometric shapes or they may resemble or evoke known objects or experiences. They may be used individually or in elaborate combinations that may be informal or formal. Decorative markings are ubiquitous throughout human societies, and their varieties seem to be limitless. Volumes are available containing samples collected from throughout the world.

Pattern perception has been extensively studied within perceptual psychology. Most of this work has to do with 
how we organize groups of lines into identifiable patterns, how we recognize them, remember them, and so on. Any arbitrary combination of lines can be a pattern; this is not so for designs. For treatments of patterns as designs, we find little in the psychological literature but must turn to art and the design professions. Many writers have attempted to determine the defining characteristics, such as order (Gombrich, 1979) and balance (Arnheim, 1982), that must be met for a pattern to be an affectively and aesthetically successful design. This endeavor has certainly not been completed, but it is clear that successful designs must satisfy some nonarbitrary and probably universal criteria.

Designs often carry specific cognitive and affective meanings. Some of these may also be the nonarbitrary consequence of a universal, or near-universal, form symbolism (Liu \& Kennedy, 1994). Other meanings can accrue through idiosyncratic associations (e.g., the wallpaper pattern that evokes one's childhood) or intentionally (e.g., logos, monograms, signatures, coats-of-arms, seals, religious and cabalistic markings, etc.). When this occurs, designs merge into the category of writings.

Writings are intended to stand for particular cognitive meanings by virtue of formally agreed on or conventionally accepted usage. Letters, words, syllables, ideographs, signs, and symbols have meanings by virtue of an arbitrary social consensus. However, the actual patterns used probably are not completely arbitrary and may well conform to some of the criteria underlying designs.

The extensive literature on the visual perception of writings covers topics as diverse as letter and word recognition, sentence comprehension and reading in general, discrimination and recognition of signs and symbols, and aesthetics and design in calligraphy and typography. These topics all involve the perception of writings as a category of markings, but rarely is this linkage among them and with other varieties of markings explicitly recognized.

Diagrams are intended to provide information visually that is available elsewhere in nonvisual form. They include charts, graphs of mathematical functions or of data, maps, plans, engineering drawings, block diagrams, and so on. Like writings, diagrams depend on socially agreed upon intentions, usage, and conventions. Unlike writings, diagrams present their information by the use of relatively nonarbitrary visual forms. The information to be communicated largely proscribes the form, and the form in turn carries the information.

Diagrams provide the mechanism whereby abstract concepts or concrete plans can be "taken out of our heads" and placed before us in observable form for further understanding, elaboration, and communication. They are visual aids to thinking and provide the external supports for the complex psychological activity that Arnheim (1971) so aptly labeled visual thinking. The visualization revolution generated by advances in computer graphics has greatly increased the quantity and types of information that can be presented diagrammatically.
The prototypical diagrams are those of geometry. Lines and circles drawn on a piece of paper are not the lines and circles of Euclidean geometry, but they greatly assist the understanding of the geometry, even though the geometry itself does not in any sense require them. Similarly when Descartes drew an abscissa and an ordinate and plotted an equation, the plot was not the equation, but the graphing of equations has greatly assisted the cognitive processes involved in entire branches of mathematics. Perhaps the most dramatic examples are the recent advances in the understanding of chaos and of fractal geometry made possible by computer-generated diagrams of seemingly simple equations.

Closely related to diagrams of mathematical functions are graphs and other diagrammatic presentations of data. No reader of this page needs to be told of the importance of the visual presentation of data to science, technology, economics, politics, and, indeed, all areas of human endeavor. The analysis of existing practice and the development of new standards and procedures is an ongoing and active enterprise (Tufte, 1983, 1990).

Equally important is the capacity to produce diagrams of complex physical objects and systems. Indeed, the cumulative nature of much of technology and science is dependent on our ability to record and transmit information diagrammatically (Ferguson, 1992). The map is not the territory, nor is it a depiction of the territory; however, without it, we cannot find our way through the territory. The plan is not the building, the engineering drawing is not the machine, and the block diagram is not the electronic system. But without them, the building, the machine, and the system would neither be conceptualized nor built. Each of these examples has an extensive literature devoted to the conceptualization, production, interpretation, and use of the relevant markings. If Homo sapiens is also Homo faber, the capacity to create diagrams is at the heart of what it means to be human.

Depictions are intended to evoke identifiable, real or imaginary, past, present, or future, possible or impossible, objects, environments, events, or experiences. Depictions include, but are not limited to, "fine art." Representational pictures are a subset of the more general category of depictions. For example, in this terminology, Albers's series "Homage to the Square" and Rothko's "Chapel" paintings are depictions, since they are intended to evoke specific aspects of human experience, but they are not representational pictures. It is widely, though often tacitly, assumed that representational pictures constitute a special class separated from all other forms of markings. We will question this assumption and examine representational pictures in detail in the next section.

To recapitulate, markings are differentiated by the intention behind their creation. Designs are intended to be decorative. Writings are intended to stand for particular, socially agreed upon cognitive meanings. Diagrams are intended to provide visualizations of data available elsewhere in nonvisual forms. Depictions are intended to evoke 
a wide range of identifiable human experiences. These, in abbreviated form, are the intentions underlying the entire range of markings.

The producer of a marking, working within the overall framework provided by the intention, is at all stages subject to a variety of constraints. These constraints are cumulative, and the markings have been listed above in the order of increasing constraints. Most fundamental of all are the limitations on what makes a pattern decorative and aesthetically successful. No one yet knows how to specify these criteria, whether the golden mean, symmetry, order, balance, simplicity, complexity, or a combination of these and others, but we do know that not any pattern will do. The constraint exists, and it is probably universal. In writing, socially agreed upon meanings provide additional constraints. Initially, the assignment of specific meanings to specific designs is probably largely, though arguably not entirely, arbitrary; however, once meaning has been assigned, the constraint is compelling. Diagrams add an extra layer of social conventions, but the primary further constraints are those provided by the data. Once the data to be presented and the general nature of the diagram have been determined, the data exert a compelling force. There must be a formal relationship between the data and the visual presentation. This constraint carries over into the category of depictions, although, in the general case, it is difficult to define. In the case of representational pictures, however, it is reasonably clear. There has to be some formal relationship between the visual information provided by the real world and that provided by the picture. The creator of the picture can select, abstract, synthesize, focus, exaggerate, and simplify; however, if the picture is to succeed as a representation, that formal relationship must be maintained. But this constraint is in principle no different from all the other constraints that, taken together, guide the hand of the creator of every marking.

\section{PICTURE PERCEPTION: A SPECIAL CASE?}

\section{What Is a Picture?}

Authors disagree widely as to what a picture is and how precisely and explicitly it can be defined. Nevertheless, definitions cluster into two general groups: those dealing with stimulus characteristics and those emphasizing the nature of the response. In practice, most writers tend to rely on an amalgam of the two.

Stimulus-oriented approaches generally agree that a picture presents, on a surface, at least some of the same visual information that would be obtained by viewing an actual object or scene. Contemporary stimulus-oriented definitions fall into two general categories: retinalimage definitions and captured-invariants definitions. Retinal-image definitions can be traced back to Euclid; however, the first, and certainly the best known, modern writer to offer an explicit formulation was probably Leonardo da Vinci (1970 ed.):
Painting is concerned with all the 10 attributes of sight; which are: darkness [and] light, solidity and color, form and position, distance and propinquity, motion and rest. This little work of mine will... remind the painter of the rules and methods by which he should use his art to imitate all the works of nature. (p. 19)

If you want to represent an object near to you which is to have the effect of nature, it is impossible... unless the spectator, when he looks at it, has his eye at the very distance and height and direction where the eye or the point of sight was placed in doing this perspective. (p. 271)

For Leonardo, the visual information from the world and from a painting ideally are identical, although the latter is necessarily less complete than the former. The representational quality of a picture depends on how closely the pattern of light resulting from viewing the picture matches that resulting from viewing the actual scene. Although never universally accepted even by Western artists, this type of definition was seized upon by students of perception and has been explicitly embraced to the present day. For Pirenne (1970, p. 10) a "representational painting is an object which sends to the spectator's eyes a complicated light flux resembling to a certain extent the light flux which would be sent by the scene it purports to represent." Cutting (1986) agrees: "Pictures are planar projections of a three-dimensional environment" (p. 30), which "represent many, but never all, characteristics presented to a single eye" (p. 33).

Captured-invariants definitions originated with Gibson (1979): "A picture is a surface so treated that it makes available an optic array of arrested structures with underlying invariants of structure" (p. 272). It is not the pattern of light but the pattern of invariants that matches, to a limited extent, the invariants available from the real object. This approach allows for selection, abstraction, synthesis, and even distortion of invariants. For example, "Caricatures can capture the same information as the object or event they depict... without duplicating their accompanying stimulation (Rosenblum, Saldana, \& Carello, 1993, p. 381).

The argument behind stimulus-oriented definitions is clear. The information in the light from the real world can be captured on a picture surface. The picture surface in turn serves as an intermediary, transmitting that information to the observer. If the information on the surface is true to the world, the information reaching the observer will also be true to the world. This seemingly straightforward argument, however, is incomplete. The picture surface is itself a real-world object that inevitably intrudes its own additional stimulus information.

A picture, no matter how "realistic" or "representational," always presents two broad classes of visual information: (1) information that would be provided by viewing the pictured real-world scene (actual or imagined) and (2) information that is unrelated to the pictured scene but comes from the real-world surface on which the picture appears (Gibson, 1979; Kennedy, 1974; Kubovy, 1986; 
Pirenne, 1970; Polanyi, 1970). These two types of information can be analyzed separately by the psychologist, and they can be decoupled by the observer, but they are always encountered together. Stimulus-oriented definitions often ignore or downplay the part of the stimulus that provides information about the surface. This results in studies that provide detailed stimulus information about the picture while saying little or nothing about the surface. Since the surface is as much a part of the stimulus as is the marking on it, these studies provide the illusion of rigorous science while masking the underlying implicit assumption that the existence of the surface is irrelevant.

In addition, stimulus-oriented definitions paradoxically do not provide a workable way of separating pictures from nonpictures. A retinal-image definition, if rigorously applied, limits pictures to precise perspective renditions. But these constitute only a very small subset of what is usually considered to be pictures. In contrast, captured-invariants definitions do seem to encompass all examples of what are usually considered to be pictures. They suffer, however, from lack of rigor. There is no objective way to determine if a particular marking does in fact capture an invariant found in the real world. Capturedinvariants definitions inevitably fall back on responseoriented criteria.

Response-oriented definitions are concerned with what a picture looks like, rather than whether the stimulus mimics real-world information. Hagen (1986, p. 4) offers a prototypical definition: a representational picture is any marking in which the real-world content is spontaneously recognized by the uneducated eye. Although it suffers from an obvious circularity, this approach accords with our intuitions by classifying as pictures many examples that are excluded by a stimulus-oriented definition (e.g., cubist portraits) and excludes some that would be included (e.g., odd, unrecognizable views of familiar objects).

In short, while some writers are more explicit than others and some are more consistent than others, at least among psychologists there is no generally accepted definition of a picture. Attempts to provide criteria rigorously separating markings into two groups, pictures and nonpictures, have proved fruitless. Most writers more or less explicitly invoke a stimulus-oriented definition while, at the same time, implicitly calling on response-defined criteria. This is far from satisfactory, but, at the moment, it may be the best we can do.

\section{The Pictorial Assumption}

Perception psychologists have universally, though usually tacitly, assumed that the similarities between the visual perception of pictures and the visual perception of the real world are deep and interesting while the differences are shallow and uninteresting. Contemporary work in machine vision and in computational models of vision has transmuted this assumption into part of the general background of beliefs that workers in the field accept without challenge. More specifically, the prevailing approach to the perception of pictures is guided by what I will call the pictorial assumption: the processes involved in the visual perception of the real world and the processes involved in the visual perception of pictures are identical. This assumption implies that what we learn by studying the perception of pictures applies directly to the perception of the real world and that what we learn by studying the visual perception of the real world applies directly to the perception of pictures. Some writers reject the pictorial assumption as a two-way street and allow traffic only in one direction or the other. Gibson, for example, maintains that we cannot learn about realworld perception by studying pictures but we can apply real-world principles to the perception of pictures. Figureground studies, in contrast, are almost always pictorial and are generally assumed to apply directly to the real world. In this section, I will argue that the pictorial assumption, two way or one way in either direction, is demonstrably false.

The pictorial assumption, however, is almost universally accepted, although rarely explicitly, as by Cutting (1986, p. 31): "These stimuli are pictures... I plan to make theoretical statements about the perception of the real world on the basis of perception of computer-generated moving images." Cutting is almost alone in explicitly stating the assumptions underlying his work, although one would assume that such a statement is a necessary condition for continuing scientific dialogue. In his use of pictures, Cutting stands in contrast to Gibson who argued against the use of pictures as surrogates for the real world while paradoxically claiming that perceiving pictures mimics realworld perception.

More commonly, writers are either unaware of or choose to ignore their implicit acceptance of the pictorial assumption. Consider, for example, the body of literature using line drawings, photographs, or computer displays as stimuli for experiments, the results of which are uncritically generalized to the perception of the real world. A few illustrations from studies of object perception and of the perception of the spatial layout of scenes will suffice.

Object perception and recognition. Pictorial displays are almost universally used to study object perception. In this literature, the pictorial assumption is not so much implied as it is ignored: the perception of pictures of objects $i s$ the perception of objects. Generalization to the real world is not questioned or even entertained as a potential issue. A few examples: (1) Shepard and Metzler (1971), in a paper that has since come to be accepted as a classic contribution, reported experiments in which subjects never viewed a three-dimensional object-line drawings were used exclusively. (2) Biederman (1987), in a widely accepted and influential theory of object recognition, presents supporting evidence based entirely on drawings and photographs. (3) The extensive body of work on face perception consists almost exclusively of studies of pictures of faces. (4) The journal Perception devoted two special issues to "Perceptual Organization and Object Recognition" (Perceptual, 1994) containing 15 papers in which not a single subject was reported ob- 
serving an actual object. These examples are offered not as criticisms of the works cited but as demonstrations of the widespread acceptance of the pictorial assumption. There have, of course, been dissenting voices, but the preponderance of work on object recognition unhesitatingly generalizes findings in picture perception to the perception and recognition of real-world objects.

Perception of spatial layout. The use of pictures to study visual spatial information is commonplace in the perception literature. Relative size, perspective, interposition, texture, shape from shading, position in the field, motion parallax, the perception of motion in general, stereopsis, and other related topics typically have been studied using pictorial displays. Indeed, many of these have traditionally been called "pictorial cues," with the implication, followed in practice, that they can properly be studied using pictures. Certainly, the vast array of studies using pictures, from the early line drawings of the Gestaltists to the current reliance on the computer screen, needs no documentation. Historically, this has not always been the case. Much early work on depth perception used real-world situations (e.g., Hollway \& Boring, 1941); more recently, neo-Gibsonians for different reasons have returned to studying real-world settings. Nevertheless, the pictorial assumption that findings from pictures can be generalized to real-world perception is the motivating force behind most contemporary work.

\section{Is the Pictorial Assumption Valid?}

The pictorial assumption is almost universally believed, but that does not make it true. Generalization from picture perception to real-world perception cannot be blindly assumed. As with any generalization in psychology, the burden of proof lies with those who support the generalization: its validity must be demonstrated, either by an acceptable general theoretical justification or by a case-by-case empirical validation. Neither of these alternatives is available. There exists no systematic attempt to validate the pictorial assumption theoretically or to demonstrate its validity empirically. In contrast, there is a variety of evidence that throws strong doubt on the validity of the pictorial assumption. (1) Phenomenologically, the two cases are different. (2) Processing of pictures does not follow the same rules of "inverse optics" that are followed when perceiving the real world. (3) Recognition of pictures of objects and scenes differs in important ways from recognition of real-world objects and scenes. (4) Behaviorally, we do not act toward pictures the way we do toward the real world.

Phenomenological differences. It is commonly accepted among writers on picture perception that pictures present a curious double aspect to the viewer: we see the surface and the picture as separate. Gibson (1979) is the most quoted: "The picture is both a scene and a surface, and the scene is paradoxically behind the surface" (p. 281). Statements of this kind are generally considered to be descriptive, but they are more properly prescriptive. Perceiving the surface is a necessary condition for perceiving the picture as a picture. "[T]he actual pattern on the surface of a representational picture must be perceived... at the same time as the objects represented are seen as a scene in depth" (Pirenne, 1970, pp. 113-114). For Pirenne, "the representation given by ordinary pictures is of a sui generis nature" (p. 166) and depends on the awareness of the surface, "qua surface," and not on the surface's flatness, texture, slant, or other visual properties. Kubovy (1986, p. 88) offers a more colorful version: "the Alberti window [i.e., the surface] differs from all others in that it functions properly only if it is not completely transparent: We must perceive the window in order to see the world." Kennedy (1974) makes a related claim that studies of figure and ground can properly be understood only on the assumption that figure-ground displays are inherently pictorial. In sum, perceiving a picture is sui generis; it is not the same as perceiving the world. Observers can tell whether they are seeing the world or seeing a picture of the world. Perceiving the picture qua picture depends on perceiving the surface qua surface.

What if the appearance of the surface is removed? Pirenne $(1970,1975)$ first systematically studied this question. "[W]here every precaution has been taken to make any awareness of the picture surface impossible,... the picture assumes a genuinely three-dimensional appearance, similar to that given by the stereoscope" (Pirenne, 1970, p. 115). This "paradoxical monocular stereoscopy," first reported by Claparède (1904, not seen by the author), has been largely ignored, as noted by Koenderink, van Doorn, and Kappers (1994) and by Enright (1991). However, it has been discussed in detail by Schlosberg (1941) and others, including Ames (1925), Enright (1991), and Koenderink et al. (1994). But these authors need to be read with care. They universally attribute the effect to a compromise between the flatness of the picture surface and the depth cues of the picture, with the relative weightings of the two changing with different viewing conditions. However, this claim ignores the fundamental insight of Pirenne: it is not the flatness of the surface but rather the appearance of a surface, qua surface, that is crucial. If we do not see the surface, the picture is no longer seen as a picture but rather as real world.

There are, then, two perceptual modes: picture and real world. Schlosberg (1941) stands out among the authors cited for recognizing this distinction: "One may see a picture as either (1) a picture representing depth or (2) as actual objects deployed in depth" (p. 602). He further stressed

the "all or none" character of the effect. We do not have a simple addition and subtraction of factors, with more or less depth resulting. The perception seems to exist in two modes. In one, it is still a picture. In the other mode, we find objects in depth. (Schlosberg, 1941, p. 603)

Schlosberg, thus, anticipated Pirenne's important conclusion by more than a quarter century.

To pursue this phenomenon further, we turn to art rather than psychology. Artists, unlike psychologists, have long been aware that they can "fool the eye" (trompe l'oeil) into perceiving a picture as real world. This effect 
is not easily accomplished, but given a successful trompe l'oeil painting, the result is dramatic. Visual inspection alone, no matter how close and detailed, will not reveal the secret that it is in fact a painting. Unfortunately, evidence for this effect is largely anecdotal. Gibson, among others, was skeptical.

The tradition of "fooling the eye" is very ancient. The assumption that a false perception of real surfaces can be induced ... is widely believed... [but] the actual binocular visual system cannot [be deceived]. A viewer can always tell whether he is looking at a picture or at a real scene... I do not believe the stories. (Gibson, 1979, p. 281)

Presumably, Gibson would not believe the following story, but it is nonetheless true. On two separate occasions, I have been so "deceived" by contemporary trompe l'oeil works that, after careful and exhaustive visual inspection, I was moved to violate the sacred canon of museum decorum. After assuring myself that no museum attendants were in sight, I touched the artwork! Only then was I able to assure myself that the apparent surfaces were in fact not real surfaces.

Placing the surface at a sufficiently great distance, as practiced by a number of Renaissance painters, makes possible large-scale trompe l'oeil effects. Pozzo's ceiling in Rome, exhaustively studied by Pirenne (1970), is probably the best known example. Cole (1992) provides the following description:

The great dome, spanning the central aisle, is actually a flat, painted canvas, while the soaring architecture above the nave windows is equally fictitious. From the great distance of the viewer's position on the floor, the surface of the nave's vaulted ceiling miraculously dissolves into a breathtaking view of the heavens. ... there is only one perfect viewpoint for each illusion (marked by marble disks on the floor)--move to one side and both structures gracefully collapse! (p. 40)

Similar effects can be achieved on a smaller scale by a combination of meticulous painting and peephole vision. This method was first demonstrated by Brunelleschi in the 15 th century (with a peephole and a mirror) and was later used in 17 th century Dutch "perspective cabinets" and, more recently, in a novel and original way by Ames in his "distorted room" (Ittelson, 1952).

In spite of all the differences between viewing a picture and viewing the real world, empirical studies directly comparing the two cases are rare, probably due to failure to see this as an interesting perceptual problem. If one accepts the pictorial assumption and believes that identical processes are involved in both cases, the idea that there might be a potential problem simply does not emerge. Nevertheless, a few investigators have approached this problem experimentally and will be discussed in the next section.

In summary, the phenomenology of seeing a picture as a picture is entirely dependent on seeing the surface. If we remove the appearance of the surface, the picture is transformed phenomenologically into real world. This is not a matter of adding more and more apparent depth until the effect is achieved. A perceived "picture" is transformed into perceived "real world" not by changing information about the picture but rather by eliminating information about the surface. A picture, no matter how complex and how carefully supplied with spatial information, is still a picture. A single portrayed object, no matter how simple and virtually devoid of all spatial information, can nevertheless be perceived as a "real object out there," provided the appearance of the surface has been eliminated. There are two distinct, discontinuous modes of perceiving, one being "picture" and the other being "real world."

Picture perception and "inverse optics." Every photograph or precisely rendered perspective painting has a single optically correct viewpoint. However, we rarely look at pictures with our eye at precisely that point, as Leonardo suggested we should. What are the perceptual consequences of such incorrect viewpoints? Leonardo was definite: "It is impossible that your perspective should not look wrong, with every false relation and disagreement of proportion that can be imagined." Leonardo based this conclusion on what has come to be called variously the problem of inverse optics, of inverse perspective, or of inverse projection (Epstein, 1995). A word of definition: Given a real-world scene and a viewpoint, linear perspective asks, what is the proper perspective rendition on a given picture surface? This is a problem in geometry; it has been worked out in detail and provides a unique solution. Any change of the viewpoint entails a corresponding change in the perspective. The problem of inverse optics asks the opposite question: Given a viewpoint and a perspective rendition on a picture surface, what real-world scene is represented? As a problem in geometry this does not have a unique solution. An unlimited number of external configurations can give rise to the same perspective rendition. A unique geometric solution requires some additional constraining assumptions (e.g., rectangularity). However, granted the appropriate assumptions, a unique geometric solution can be reached, and that solution is sensitive to any changes in the perspective rendition due to changing viewpoints.

Perception of the real world seems to follow this pattern; it is immensely sensitive to changes in the perspective view. As we move about the world, our visual system receives constantly changing views that are woven together into the perception of a continuous and stable world. If changes in the perspective views are not consistent with a stable world, the world will appear to move and distort, as illustrated by Pozzo's ceiling and as shown, for example, in some of the "Ames demonstrations" (Ittelson, 1952) and the phenomenon of "illusory concomitant motion" (Peterson, 1986).

If we look at pictures from any point except the optically correct viewpoint, the pictorial assumption coupled with inverse optics predicts the same effects. Leonardo's prediction should come to pass, but we all know that doesn't happen. We walk through museums and thumb through our photograph albums; everything looks fine 
even though our eyes are rarely, if ever, at the optically correct viewpoint. This apparent refusal of picture perception to follow the rules of inverse optics (Pirenne, 1970; Polanyi, 1970) has been labeled the robustness of perspective (Kubovy, 1986; Nicholls \& Kennedy, 1993). This phenomenon poses a critical problem for the understanding of picture perception. Perceiving the real world is sensitive to small changes in perspective; perceiving pictures is seemingly indifferent to large changes.

Attempts to reconcile this apparent contradiction are part of the larger study of how accurately we can judge the spatial layout represented in a picture and how it is affected by viewing condition (Ellis, Kaiser, \& Grunwald, 1991). The problem from the standpoint of inverse optics has been stated concisely by Sedgwick (1991): "What effect does viewing a [precise perspective] picture from the wrong location have on the virtual space represented by that picture?" (p. 460). The geometrically predicted distortions are readily calculated (Sedgwick, 1991) and involve distortions of size, shape, distance, orientation, and other characteristics.

Explanations for the reported failure to perceive these distortions fall into four categories as summarized by Rogers (1995): (1) compensation-the visual system compensates or corrects for the incorrect viewpoint (Kubovy, 1986); (2) minimal distortion-distortions are so small that they are unnoticed or irrelevant (Busey, Brady, \& Cutting, 1990; Cutting, 1987); (3) invariant information-some information in the picture remains invariant under changes in viewpoint (Sedgwick, 1991); (4) distortions are perceived - some distortions actually are perceived although they may not be noticed or reported (Cutting, 1988). To these I would add (5) compromiseconflicts between perceptual information provided by the picture and by the picture surface are resolved in some form of perceptual compromise (Sedgwick, 1991).

Drawing on a comprehensive review of the relevant experimental literature, Rogers (1995) rejects the compensation hypothesis but finds evidence to support the next three possibilities, each of which serves as a constraint on the degree of robustness that can be achieved. Pictures, she points out, are artifacts, and the robustness that is commonly perceived results from artists and photographers consciously or unconsciously incorporating these constraints into their pictures. This conclusion is consistent with that of Nicholls and Kennedy (1993), who suggest the possibility of a continuum from robust to fragile as a function of viewing conditions in conjunction with the manner in which the pictorial information is presented. These conclusions, however, neglect the fifth possibility above: The spatial information provided by the picture surface may interact with the pictorial information, requiring some form of compromise (Koenderink et al., 1994; Sedgwick, 1991). Cutting and Vishton (1995) have provided a new approach to how such compromises might be understood in both pictorial and real-world perception, and Sedgwick and Nicholls (1993) conclude that "it may thus be possible to describe pictorial perception as arising from the same processes as those used in ordinary nonpictorial perception" (p. 109).

These experimental and theoretical issues are subject to continuing study and cannot be resolved at this point. Their relevance to the pictorial assumption will be considered in terms of four issues.

1. Robustness of perspective. Either the presence or the absence of robustness raises questions. In cases of robustness, changes in perspective are ignored. In the absence of robustness, readily available visual input from the surface is ignored. Neither of these cases occur in real-world perception. How can either the presence or the absence of robustness be reconciled with the known facts of real-world perception?

2. Real-world spatial perception versus the virtual space of pictures. Judged distances in pictured scenes closely approximate distances judged while viewing the actual scenes (Rogers, 1995). But the virtual distances in a picture are vastly different from the perceived spaces of the real world. If the same processes are involved in perceiving pictures and perceiving the real world, how can they possibly arrive at such very different end points?

3. Nonperspective pictures. Pictures that present accurate perspective information are used for the study of inverse optics, but they constitute only a small fraction of the vast array of representational pictures that have been produced historically and crossculturally. A wide variety of other geometric transformations have been used to produce representational pictures (Hagen, 1986). Even within the perspectivist tradition, departures from perfect perspective in whole or in part for stylistic reasons are common. In other cases, perspective is deliberately ignored, or a mixture of different geometries is used, including the interesting case of parallel perspective, which assumes an infinite viewing distance. The automatic application of inverse optics to all of these examples would lead to chaos. There are too many cases that present no perceptual problem to the viewer but for which a rigorous inverse optics solution would yield grotesque results. Can inverse optics be a general solution to picture perception when, at best, it can apply to only a small fraction of admittedly representational pictures? If it is not a general solution, then where is its utility as an explanatory principle?

4. Gibsonian invariants. Gibson and his followers have a view of picture perception that makes the entire question of inverse optics irrelevant. Regrettably, they have no procedures for making testable predictions in as principled and precise a way as that offered by inverse optics. Nevertheless, can we reasonably ignore that approach to the perception of representational pictures?

The preceding four questions in turn call into question the validity of the pictorial assumption, at least as far as representational pictures are concerned. The most conservative conclusion is that the pictorial assumption is open to grave doubt and must be approached with caution.

Object and scene recognition. Starting almost a quarter century ago (Ittelson, 1970, 1973; O'Keefe \& Nadel, 1978 ) and with growing evidence from many directions, 
the perception of objects and the perception of environments have been treated as separate domains with different, though overlapping, mechanisms and functions. Today, the literatures on object recognition and on spatial perception are largely isolated from each other. Object perception has become synonymous with object recognition, studied almost exclusively using pictures with results generalized to the real world. We note parenthetically that this description does not apply to the Gibsonian approach, which has been relatively silent on object recognition. Gibson (1979), while claiming that we can apply real-world principles to the perception of pictures, was also quite explicit about object perception: "What we perceive when we look at objects are their affordances" (p. 134). Since the pictured object affords us nothing, an obvious contradiction arises. Gibson, of course, was aware of this problem, although he never fully came to grips with it. We shall consider this issue later, but, first, we return to the mainstream of object recognition research.

Investigators of object recognition are united on a methodology using pictures as stimuli, but they are fragmented as to what they mean by object recognition. The literature provides many idiosyncratic definitions but has yet to settle on a generally recognized definition specifying a common problem area. In the absence of such a definition, I will approach the question by discussing four more or less orthogonal dimensions along which various approaches differ.

1. Conscious or unconscious? Some investigators define object recognition as the unconscious, implicit accessing of structural descriptions stored in memory; other investigators believe that conscious, explicit awareness is required. It would seem evident that a complete theory of object recognition would encompass both.

2. Naming alone or more complex cognitive and behavioral descriptors? Many investigators consider the ability to name an object to be the necessary and sufficient condition for indicating recognition. But, surely, there is more to recognizing an object than the ability to name it. My dog recognizes me by any reasonable meaning of the term, but he has yet to call me by name. Unless we wish to draw a firm line between human and nonhuman recognition processes, naming cannot be the sole criterion. Adding other behavioral and cognitive indicators of recognition might introduce complications, but perhaps they are needed to capture the phenomenon.

3. Basic level categories or particular exemplars? Much of the literature is explicitly concerned with basic level categories (e.g., that is a dog, a cup, a house). But a sizable, though different, literature (face recognition, in particular) studies the identification of specific individuals. This would not seem to be an "either-or" issue. Perhaps identifying basic level categories is a necessary part of the process of object recognition; but it cannot be all of it. Certainly, the ability to identify individuals is biologically and psychologically essential.

4. Small-scale object or large-scale scene? Most recognition work deals with isolated, small-scale objects.
However, we can also recognize large-scale scenes and all scales in between, and some investigators are moving in that direction. Is recognition of objects fundamentally different from recognition of scenes? More generally, do recognition processes vary as a function of scale? A psychology of recognition might be expected to cover the full range of scale.

A complete psychology of object recognition would encompass the entire space identified by these four dimensions and, undoubtedly, others. Whether the use of pictures offers a suitable methodology for studying this entire range of problems is, at least, debatable. If a complete psychology of picture recognition were to be worked out, it is by no means obvious that it could be transferred bodily to real-world recognition. This is, at heart, an empirical question that needs to be approached systematically. The use of line drawings and photographs to study certain aspects of the problem may turn out to be appropriate; at the moment, we have very little evidence. As the phenomena under investigation become more complex, as we become concerned with phenomenologically rich and detailed real-world objects and environments, and as the indicators of recognition become cognitively and behaviorally more meaningful, the use of pictures may be expected to become progressively more problematic. Almost a century and a half ago, Oliver Wendell Holmes (1859) offered an extreme statement of reliance on pictures as substitutes for real-world objects. Captured by the euphoria surrounding the newly invented photostereogram, he wrote,

Form is henceforth divorced from matter. In fact, matter as a visible object is of no great use any longer, except as the mould on which form is shaped. Give us a few negatives of a thing worth seeing, taken from different points of view, and that is all we want of it. Pull it down or burn it up, if you please. (Holmes, 1859, p. 747; italics in original)

The years have proven him wrong, and the psychology of object and scene recognition might do well to consider that verdict.

Behavioral differences. We do not act toward pictures the way we act toward the real world. If I ask you to fill my cup with coffee, you will not try to pour coffee into the picture, even though I have already informed you that it is "my cup." This seemingly trivial and obvious point becomes significant when we recognize that the behavioral aspects of picture perception relate to the phenomenological. If we treat the picture such that it appears to be real world, we also act toward the picture as if it were real world. Smith and Smith (1961) provide an often cited experimental demonstration of this phenomenon. Two groups of subjects looked through a peephole into a room, one group seeing the actual room and the other seeing a photograph of the room displayed so that the surface was not visible. Both groups threw a ball at targets in the actual room. There was no systematic difference between groups either in the way they threw the 
ball or in their impressions that they were actually looking into the real room. For a picture to be a picture, the scene and the surface must both be visible to the viewer. Remove the appearance of the surface and the picture ceases to be a picture and becomes the real world, phenomenologically and behaviorally. Not only will you say it really is "my cup" but you will actually try to pour coffee in it.

The inability to act with respect to pictures poses a problem for theorists who believe that action and perception are inextricably linked. Gibson (1979), while claiming that perceiving pictures follows the same processes as perceiving the real world, also claimed that "the full awareness of surfaces includes their layout, their substances, their events, and their affordances" (p. 255). But "strictly speaking, all we perceive directly are surfaces as such. If so, we should not speak of the perception of a picture but of a nonperceptual kind of apprehension" (Gibson, 1980, p. xv). Pictures do not provide affordances: this contradiction persistently worried Gibson and his followers (Stoffregen, 1993), who have for the most part used real-world settings for perceptionaction research (Flynn, 1994; Warren, 1984).

The difference in behavior toward pictures and toward the real world touches on a fundamental issue of perceptual theory. Perception of the world is complexly related to action in the world. The adaptive value of visual systems depends on their ability to guide effective action in the world, although the exact nature of the processes involved remains obscure. This issue will not soon be settled, but we are here concerned with the narrower question of whether the real-world relationship between perception and action casts doubts on the pictorial assumption. It can be argued that, although we cannot act directly on pictures, verbal judgments about actions - or, in limited cases, some actual actions - made in response to pictures can be accurate predictors of action in the real world. Judgments of distances represented in pictures closely approximate similar judgments in response to the actual scene (Rogers, 1995). Might not the same be true for judgments concerning actions? Even this limited use of pictures to study real-world actions, however, is thrown into question by the work of Goodale and Milner (1992), who provide evidence for at least a partial dissociation between neural pathways for conscious visual perception and for visually guided action. Inferences or other indirect measures of action based on pictures therefore become highly problematic. There may, of course, be cases in which such measures can be used effectively, but their validity cannot be assumed in advance.

The proposition that perception and action are intimately related is a basic tenet of all perceptual theories, and the explication of that relationship poses a continuing challenge. Actions guided by real-world visual perception are fundamentally different from actions growing out of the perception of pictures and of markings in general. At least to the extent that the attainment of correct perceptions is a necessary condition for survival, or for effective action, the perception of the real world and the perception of pictures are profoundly different. This topic will be addressed more fully in the final section of this paper.

\section{The Pictorial Assumption Revisited}

The similarities between looking at pictures and looking at the real world are so striking that it would seem intuitively obvious that the same perceptual processes must be involved in the two cases. This intuition has been incorporated into contemporary perceptual research in the form of the pictorial assumption. We have examined this assumption and found it lacking in many respects. First, the definition of a picture, even a representational picture, is so unclear that it is questionable whether the term refers to a coherent class. Furthermore, even granting the category of pictures, we have found important differences between real-world perception and the perception of pictures in the areas of phenomenology, processing in terms of "inverse optics," recognition, and behavior. A large body of evidence suggests that the pictorial assumption in the strong form presented earlier in this section and as generally accepted in the psychological literature is false. The most conservative response to this evidence is the Pictorial Assumption (Corrected): The processes involved in the visual perception of the world and in the visual perception of pictures differ in important ways. Generalizations from one to the other must be undertaken with caution.

This conclusion has implications for the study of realworld perception. It has been argued "that the widespread use of two-dimensional stimuli in perceptual experiments has led ... to the development of theories that are of little value in accounting for normal everyday perceptions" (Wade \& Swanston, 1991, p. 197). At the least, an experimental and theoretical program is needed to determine if, and under what conditions, generalizations between pictures and the real world may be valid. The findings of this program, taken seriously, could result in important contributions to, and revisions of, our understanding of the psychology of perception. Furthermore, the implications of this conclusion go beyond the psychology of perception. Any general model of human cognition must be able to differentiate between the real world and pictures of that world and to respond appropriately and differently to each. To my knowledge, no modelscomputational, neural network, or any other-have addressed this issue.

In summary, the perception of pictures of objects, places, and events differs in significant ways from the perception of the objects, places, and events themselves. Generalizations to and from studies using pictures as stimuli must be carefully examined. Pictures are only one of the many categories that fall under the classification of markings. They do not constitute a separate and special group standing in isolation outside the general heading. How studies of the perception of markings and of the perception of the real world can inform each other requires further theoretical and empirical analysis. 
Markings are everywhere. We perceive them effortlessly and weave those perceptions seamlessly into the ongoing fabric of our perceptions of the world. Markings are so obvious that it has seemed unnecessary to subject them as a general class to critical inquiry. Nevertheless, it is to that inquiry that we now turn.

\section{PERCEIVING MARKINGS}

The study of the perception of markings is an important field in its own right. What markings are about, how they are processed, what is a correct perception of a marking, and how the perception of markings relates to ordinary perception will be addressed in this section.

\section{What Perceptions Are About: Real World and Markings}

What real-world perception is about is clear in broad outline, although different authors express it in different terms with different theoretical implications. For Gibson (1979), vision's "function is to help the observer cope with the environment" (p. 239). For Marr (1982), vision provides information that is "useful" for the organism. These authors, representing the direct and the computational approaches to perception, agree, as do most other perception theorists, on the overall function of visual perception.

The visual systems of all reasonably complex organisms provide useful information about the ongoing states of relevant aspects of the immediately present world. I will summarize this long phrase with the term existence: Real-world perception is about existence. Let us examine the various components that make up this definition. Useful information about the world helps the individual cope with and act effectively in the world. That is the adaptive function of vision: Organisms with visual systems that provide more useful information replace those with less useful visual systems. Ongoing states of the world reflect the constant change and flux of the environment. No individual lives in a static world, and perception is not a series of static views. The world provides multiple sources of constantly changing information, and perception maintains a running contact with that flow. But within never-ending change, there are elements of continuity and stability, and perception uses those elements to establish a world of relative stability and constancy. Relevant aspects of the world vary from organism to organism, from individual to individual, and, for the same individual, from time to time. While broadly attuned to those aspects of the world that are generally relevant, perception explores, selects, and attends to specific aspects that become important as the individual's status changes over place and time. It is this immediately present world that perception is concerned with. Perception does not provide information about yesterday's world or tomorrow's, nor about far away times and places; it is about the immediate present. The immediate present is notoriously hard to define; it is certainly a "specious present," and its spatial and temporal bound- aries are flexible, within limits. Real-world perception is about the here and now. It is a closed process: There is a "real world out there," and the information available to perception is defined by that world. Perception is ongoing, fluid, continuously changing, but, at every moment, it converges on the immediately present world.

In broad outline, then, ordinary perception is about the ongoing states of relevant aspects of the immediately present world (i.e., existence): It is exploratory, using multiple sources of information to arrive at the perception of a unique and stable world by means of a convergent, closed process.

If the perception of the world is about existence, what is the perception of markings about? Markings do not occur naturally in the real world; they exist as human expressive and communicative artifacts. The perception of markings must necessarily be about that expressive and communicative content. Markings are important because they directly influence the thoughts, feelings, and images of the perceiver, or more precisely, the affective, cognitive, and imaginal content attributed to a particular human expressive and communicative artifact, made possible by the decoupling of that content from its real-world source. I will substitute for this long and cumbersome phrase the term affectance, from the dictionary definition of the verb to affect, "to impress or influence (the mind or feelings)." If the perception of the real world is about existence, the ongoing state of the world, the perception of markings is about affectance, the ongoing state of thinking, feeling, and imaging about the world.

Affectance is not about the immediately present world. The informational content of markings is decoupled from the real-world situation in which they are encountered. Whether design, writing, diagram, or depiction, the marking provides information that affects the viewer's thoughts, feeling, and images about something other than the here-and-now source of the marking. And, unlike the real-world source of ordinary perception, the marking stands as a single, limited, and completely defined source of visual information. There is no opportunity for further exploration, although more detailed examination is usually possible, and obtaining information about the marking from other sources can be an important part of the process. From that defined beginning, starting with a single, concrete instance, the perceptual system generates a range of alternative possibilities that are essentially divergent; they radiate out in a variety of directions from the marking as a starting point. This is an open-ended process with no predetermined end point. In short, the perception of markings is about the cognitive, affective, and imaginal content attributed to particular human artifacts (i.e., affectance): Using a fixed, fully defined, single source of information, it generates a range of possibilities by means of a divergent, open-ended process. While real-world perception keeps us in continuous, intimate contact with the external realities of existence in the here and now, the perception of markings transports us into the inner world of affectances. 


\section{The Correctness of Perceptions: Real World and Markings}

An assessment of the correctness of perception has always been, and should be, a part of the overall study of perception. Real-world perception provides information about existence-about the relevant objects, spatial layouts, and events in the immediately present external world. Assessing correctness would seem to be a simple matter of comparing the perception of existence with the actually existing world. But the perceiving individual cannot do this. No organism has access to a separate independent description of the world against which to hold up its perceived description of that world. It simply cannot be done. An organism can determine if its perception of the world is correct only by acting in that world (Ittelson, 1960, pp. 22-23). These considerations led Ames to describe perceptions as "prognostic directives for action" and Gibson to invent the felicitous concept of "affordances." "The affordances of the environment," Gibson $(1979$, p. 127) writes, "are what it offers the animal, what it provides or furnishes, either for good or ill... Affordance... refers to both the environment and the animal... [and] implies the complementarity of the animal and the environment." Gibson $(1979$, p. 129) further states, "An affordance is neither an objective property nor a subjective property.... [It] cuts across the dichotomy subjective-objective.... It is equally a fact of the environment and a fact of behavior." In dealing with the correctness of perception, I will adopt the term affordances, as Gibson defined it, but without accepting his theorizing about the perceptual processes involved. Furthermore, as explicit in Ames and implicit in Gibson, affordances are future oriented; they are predictive in nature. The correctness of perception is not a static property. Perceived affordances tell us what we can do in the world, and their correctness depends on how good a guide they are in carrying out commerce with the environment. The correctness of perception unfolds in the course of ongoing action.

Correctness carries with it the possibility of incorrectness - of misperception. For many writers misperceptions pose a major conceptual problem. They should not. The visual system is indeed remarkable, but it is not perfect, nor should we expect it to be. The extraordinary fact is not that we occasionally misperceive but that we so rarely do. The accuracy of perceptual information is perhaps the most consistent and impressive finding of studies of visual perception. Along with other organisms, humans exhibit the capacity to generate faithful and useful information about the relevant aspects of the external world and to act effectively on the basis of that information. This is essentially a tautology: Its truth is given by the existence of the organisms. Survival depends on effective and successful action in the environment. Successful and effective action in turn requires reasonably accurate information about the environment and is ultimately the only meaningful criterion for assessing the correctness of perception. Any organism that generates consistently incorrect information about relevant aspects of its environment simply is not going to survive. Failure to survive may be due to many causes, but survival is proof positive of the overall correctness of the perception of affordances.

The correctness of the perception of markings poses a radically different problem. There is no objective description of a marking that is analogous to a description of the real world. The closest we can get to it is a description of the two-dimensional pattern of edges, luminance, and so on. This is a far cry from what we mean by a description of the world, and it serves as only the starting point for perceiving that world. But as soon as we go beyond that, there is no objective description of the marking that exists independent of the fact of being described. In short, there exists no independent, objective criterion against which to assess the correctness of the perception of markings. But even if there were such a description, the perceiving individual would have no more access to it than to an independent description of the real world. Nor does an appeal to the consequences of action help. Markings do not afford anything in the real world. There is nothing one can do with or to a marking except contemplate it, inquire about it, or change it.

What then do we mean when we speak of the perception of a marking, and is there a sense in which that perception can be correct or incorrect? This difficult question has been addressed by many writers whose influence can be seen in these pages (Berger, 1977; Danto, 1981; Gombrich, 1969; Goodman, 1976; Levinson, 1993; Roskill \& Carrier, 1983). I will approach this question by discussing four issues. (1) "Correctness" implies a comparison, for which there are two candidates: the original intent of the maker of the marking (Bloom, in press) and the meaning of the marking as currently embedded in social process. Both are legitimate meanings; which one is appropriate depends on the context. (2) In the general case, they lead to different conclusions, and neither provides a unique, principled answer. (3) Nevertheless, we usually are satisfied that we deal with markings reasonably correctly and appropriately. This pragmatic approach to correctness is made possible by constraints stemming from both the original intent and current usage. (4) The lack of a general, principled way to determine if the perception of a marking is "correct," far from being a weakness, is a strength. The perception of markings is openended, fostering individual differences and the exercise of creativity. This does not, however, mean that every marking is an open-ended invitation to fantasy. The concept of the correctness of the perception of a marking is a meaningful one, and the search for that correct perception is a legitimate endeavor.

Any marking exists as a consequence of someone's intention to express or communicate some affectance, some thought, feeling, or image, by creating a specific type of artifact, a marking. The correct interpretation of any communication is what the communicator intends to communicate. To perceive a marking "correctly" is to 
correctly realize that intention. But as a practical guide to assessing the correctness of the perception of markings, this approach immediately runs into problems.

At least three levels of intent underlie the creation of any marking: the immediate content, the medium used to express that content, and the general principle intended to be conveyed. While this is true of all markings, it is most easily demonstrated in art. The immediate content of, for example, Picasso's "Les Demoiselles d'Avignon" is 5 women. There is no doubt that Picasso intended to paint 5 women, and to perceive this painting as a picture of 5 women is certainly correct. But it is equally obvious that Picasso intended to do more than paint another picture of 5 women. He chose a particular medium, a constellation of design, form, color, paint, scale, and so forth, because he intended to evoke a particular affectance, a particular cognitive, affective, and imaginal state in the viewer. In all markings, the medium is, and always has been, at least part of the message. But underlying the choice of both content and medium is the intention to convey a general principle-in Picasso's case, a new way of looking at art and at human existence. This complex interweaving of levels of intent, so clearly illustrated in art, is characteristic of all markings although frequently hidden under a patina of accepted customs and usage. Even a graph in a scientific article is not immune. The immediate intent is to present a set of data, but the choice of how those data are presented - the medium used-is heavily dependent on what aspects of the data are intended to be emphasized, and that in turn grows out of what general principles and conclusions are intended to be drawn. The intent underlying any marking is a difficult and elusive quarry.

The creation and the subsequent perception of a marking involve a definite sequence of events: the creator of the marking starts with a set of intentions and produces a marking; the perceiver starts with the marking and tries to reconstruct the intentions. We need to examine this path in more detail. If there were a clear causal sequence, with intentions fully determining the marking and then being uniquely derivable from the marking, correct perception, in terms of recovering the original intent, would present no problem. There would always be, at least in principle, a correct solution. But that turns out not to be the case. Far from being a recognizable causal chain, the route from intention to marking and from marking back to intention is strewn with multiple choices and complex contingencies. This is also true of the creation and design of artifacts in general (Petroski, 1993), of which markings are a special case.

Markings, like all artifacts, start with an intention or purpose and end with a physical structure or form. If the process is successful, the form actualizes the intention so perfectly that it seems inevitable. Nevertheless, it is the product of a continuous series of choices based on social practices, individual experiences, and aesthetic judgments (Willats, 1990). The considerations impinging on and constraining future choices are contingent on earlier choices in a process that is as idiosyncratic and unique as the individuals involved. Many of the decisions along the way are "rational." They are in principle "computable" on the basis of some hypothetical algorithm. But some, perhaps most, are not. They are based on a feeling on the part of the creator of the marking that, of all possible paths, this one is the "right" way to go. This is most obvious in the case of the creative artist, but it is equally true for the creators of all types of markings. The number of potentially acceptable designs seems to be as countless as the number of possible sentences. Presenting quantitative information by diagrams offers an equally endless array of possibilities. "To envision information ... is to work at the intersection of image, word, number, art.... And the standards of quality are those derived from visual principles that tell us how to put the right mark in the right place" (Tufte, 1990, p. 9). These decisions are properly termed aesthetic. "When is it finished?" is perhaps the most interesting decision of all and represents the final creative aesthetic judgment. No marking can be created without a continuing exercise of aesthetic judgments, although they may on occasion be so hidden in established practice as to be unrecognizable. And the thought, feeling, or image the marking is intended to communicate or express cannot be separated from the aesthetics of the marking.

Now another individual is faced with the marking. What is it? The most obvious solution is to derive from the physical form the original intent of the maker. The wonder of art is that it "evokes a corresponding resonance in the mind of the maker and the recipient" (Arnheim, 1993 , p. 197). But this is rarely achieved. Between the original intent and the final markings are many possible "alternative histories," only one of which was followed and cannot in principle be retrieved from the marking alone. We can, of course, ask the creator of the marking, if available, what the marking is intended to mean. This may work in a few simple cases, but, in the general case, it runs into a curious paradox. This seemingly innocuous question asks the originator of the marking to produce a second marking that will elucidate the first. Will this marking be more easily understood than the original? Presumably not, or it would have been created in the first place. So we enter an endless regress. In most cases, perhaps fortunately, the originator is not accessible; in others, the original intent may be considered irrelevant, as with "found" art or religious icons used as decorative pieces. We can, as an alternative approach, ignore the original intent and assess the marking entirely within the nexus of contemporary social structure and practice. But this produces multiple answers, no one of which can be demonstrated to be uniquely correct. In actually dealing with markings, we inevitably combine both approaches. There is, in principle, no way of determining a single, stable answer to the correct perception of a marking.

Nevertheless, in dealing with markings, we do not experience anarchy; instead, we typically perceive a definite meaning that we are confident is correct. We can do this because the form or structure of the marking does provide powerful constraints on the meaning. These are 
the same constraints that guide the hand of the maker of the marking, and they have been listed earlier: (1) the inherent constraints on what makes a design decorative or aesthetically satisfactory, (2) the socially agreed upon meanings and usages surrounding writing, (3) the conventions regarding the construction of diagrams that are further constrained by the nonvisual data, and (4) the need for depictions of all kinds to have some formal relationship between the visual information provided by the world and that provided by the depiction. These constraints rarely lead us astray. Markings that have the form of a random array of lines rarely are intended to be designs. Markings that have the form Have gone to the store are rarely intended to mean $\mathrm{Am}$ in the kitchen cooking dinner. Markings that have the form of a street map are rarely intended to be abstract portraits or graphs of data. Markings that have the form of a cat are rarely intended to represent dogs. When we couple these constraints with equally powerful constraints imposed by current social usage, very little room may be left for multiple interpretations.

This process works; we generally deal successfully with the vast numbers of markings we daily encounter. But this is a pragmatic, not principled, solution to the problem of the correctness of the perception of markings, and it can be wrong. Suppose, for example, that someone puts a complex arrangement of lines and colors on a canvas and declares, "That is a nude descending a staircase." You and I and all our friends look at it and declare, strongly and unanimously, that, whatever else it may be, it most certainly is not a nude descending a staircase. But it turns out that we are wrong. Similarly, Have gone to the store may be intended to be read as I am angry with you and don't want to be home when you arrive. The perception of markings is a pragmatic affair enmeshed in a complex of individual, social, and cultural processes applied to the interpretation of forms that always underdetermine meanings.

Individual, social, and cultural meanings are in constant flux. So also are the perceptions of markings: witness the "Nude Descending a Staircase." The perception of markings is subject to both long-term and sudden, "catastrophic," changes. The perception of markings-or more generally, the perception of affectances-is divergent and open-ended. This is the dilemma, the challenge, and the opportunity facing us every time we create a marking. We construct a form, but we can never fully determine how that form will be perceived. Each perceiver can, and indeed must, perceive it idiosyncratically to a greater or lesser extent.

In summary, the correctness of real-world perception and the correctness of the perception of markings have very different meanings. Correct perceptions of the world provide information that helps us successfully negotiate the immediate world in which we find ourselves. That is their adaptive function. Correct perceptions of markings provide affectances-thoughts, feelings, and images - that help us contemplate (Arnheim, 1993), understand, and create a world other than the one in which we immediately find ourselves. That is their adaptive function.

\section{Affectances: Markings and Real World}

To this point, we have considered the perception of affectances only with respect to markings. This is an appropriate starting point; markings reveal affectances stripped of their real-world trappings, leaving them exposed to our scrutiny. But the perception of affectances is not limited to markings. Markings imperceptibly merge into bas-reliefs, then to sculpture, and along one path to dance and drama, while another path leads us generally to artifacts and on to the entire built environment. The paths converge on the full-scale environment, natural and built. As a concluding note, I suggest that every situation we encounter has a dual personality: It is the real-world setting in which we act out our lives, and it also provides the realworld occasions from which we can peel off the affectances that mold and direct our inner lives.

The contrasts between the perception of the world and the perception of markings are presented in the Appendix.

\section{SUMMARY AND CONCLUSIONS}

Markings are two-dimensional patterns that do not convey information about the real-world surfaces on which they appear; their informational content is decoupled from its real-world source. Markings are intentional, expressive, and communicative human artifacts. The role they play in visual perception is quite different from that of ordinary, real-world perception. Markings do not tell us about the world; they directly influence the cognitive, affective, and imaginal content attributed to the marking. If ordinary perception is about the existence of the real world, markings are about the affectances, the thoughts, feelings, and images of the observer.

The perceptual role played by markings is closely tied to the ways in which markings are processed by the visual system. Ordinary perception is exploratory, using multiple sources of information to arrive at the perception of a unique and stable world by means of a convergent, closed process. In contrast, the perception of markings starts with a fixed, fully defined, single source of information and generates a range of possibilities by means of a divergent, open-ended process.

Since different functions and processes are involved in the perception of markings as contrasted to everyday perception, generalizations of findings from one to the other must be undertaken with great caution. In particular, the use of markings as surrogates for the real world in perceptual experiments needs to be examined. It is at least arguable that theories based on experiments using markings as stimuli have little to tell us about everyday, real-world perception. A comprehensive theoretical and experimental analysis of the possibilities and limitations of generalizations between real world and markings is needed before we can safely interpret the large amount of data already accumulated. 
The perception of markings is an important research field in its own right. Differences between the perception of markings and real-world perception must be reflected in any approach to perception that hopes to be complete, including attempts to model perceptual processes, whether computationally, by networks, or directly physiologically. Identification of the functions and processes that are restricted to the perception of markings, those that are limited to real-world perception, and those that overlap constitutes a major research program. Finally, I suggest that the extension of the concept of affordances to real-world situations is a profitable direction for future research.

\section{REFERENCES}

AMES, A., JR. (1925). The illusion of depth from single pictures. Journal of the Optical Society of America, 10, 137-148.

ARNheIM, R. (1971). Visual thinking. Berkeley: University of California Press.

ARNHEIM, R. (1982). The power of the center. Berkeley: University of California Press.

ARNHEIM, R. (1993). From pleasure to contemplation. Journal of Aesthetics \& Art Criticism, 51, 195-197.

BERGER, J. (1977). Ways of seeing. New York: Penguin.

BIEDERMAN, I. (1987). Recognition-by-components: A theory of human image understanding. Psychological Review, 94, 115-147.

BLOOM, P. (in press). Intention, history, and artifact concepts. Cognition.

Busey, T. A., Brady, N. P., \& CutTing, J. E. (1990). Compensation is unnecessary for the perception of faces in slanted pictures. Perception \& Psychophysics, 48, 1-11.

CABE, P. A. (1980). Picture perception in nonhuman subjects. In M. A Hagen (Ed.), The perception of pictures (Vol. 2, pp. 305-343). New York: Academic Press.

ClaPaRÈDE, E. (1904). Stéréoscopie monoculaire paradoxale [Paradoxical monocular stereopsis]. Annales d'Oculistique, 132, 465-466.

Cole, A. (1992). Perspective. New York: Dorling Kindersley.

Cutting, J. (1986). Perception with an eye for motion. Cambridge, MA: MIT Press.

Cutting, J. E. (1987). Rigidity in cinema seen from the front row, side aisle. Journal of Experimental Psychology: Human Perception \& Performance, 13, 323-334

CutTing, J. E. (1988). Affine distortions of pictorial space: Some predictions for Goldstein (1987) that La Gournie (1859) might have made. Journal of Experimental Psychology: Human Perception \& Performance, 14, 305-311.

Cutting, J. E., \& Vishton, P. E. (1995). Perceiving layout and knowing distances: The integration, relative potency, and contextual use of different information about depth. In W. Epstein \& S. Rogers (Eds.), Perception of space and motion (pp. 69-117). New York: Academic Press.

DanTO, A. (1981). The transfiguration of the commonplace. Cambridge, MA: Harvard University Press.

DeLoache, J. S., \& BURNS, N. M. (1994). Early understanding of the representational function of pictures. Cognition, 52, 83-110.

Ellis, S. R., Kaiser, M. K., \& Grunwald, A. J. (Eds.) (1991). Picto rial communication in virtual and real environments. New York: Taylor \& Francis.

ENRIGHT, J. T. (1991). Paradoxical monocular stereopsis and perspective vergence. In S. R. Ellis, M. K. Kaiser, \& A. J. Grunwald (Eds.), Pictorial communication in virtual and real environments (pp. 567576). New York: Taylor \& Francis.

EPSTEIN, W. (1995). The metatheoretical context. In W. Epstein \& S. Rogers (Eds.), Perception of space and motion (pp. 1-32). New York: Academic Press.

Fein, S. (1993). First drawing: Genesis of visual thinking. Pleasant Hill, CA: Exelrod.
Ferguson, E. R. (1992). Engineering and the mind's eye. Cambridge, MA: MIT Press.

FLYNN, S. (1994). The perception of relative mass in physical collisions. Ecological Psychology, 1, 227-251.

FreEMAN, N. H. (1995). The emergence of a framework theory of pictorial reasoning. In C. Lange-Kuttner \& G. V. Thomas (Eds.), Draw ing and looking (pp. 135-146). New York: Harvester Wheatsheaf.

GiBSON, J. J. (1979). The ecological approach to visual perception. Boston: Houghton Mifflin.

GIBSON, J. J. (1980). Foreword: A prefatory essay on the perception of surfaces versus the perception of markings on a surface. In M. A Hagen (Ed.), The perception of pictures (Vol. 1, pp. xi-xvii). New York: Academic Press.

Gombrich, E. H. (1969). Art and illusion. Princeton, NJ: Bollingen Series/Princeton University Press.

GomBRICH, E. H. (1979). The sense of order. Ithaca, NY: Cornell University Press.

Goodale, M. A. \& MiLner, D. A. (1992). Separate visual pathways for perception and action. Trends in Neurosciences, 15, 20-25.

Goodman, N. (1976). Languages of art. Indianapolis, IN: Hackett.

HAGEN, M. A. (1986). Varieties of realism. New York: Cambridge University Press.

Herrnstein, R. J., \& Loveland, D. H. (1964, October 23). Complex visual concepts in the pigeon. Science, 146, 549-551.

Hollway, A. H., \& BoRING, E. G. (1941). Determinants of apparent visual size with distance variant. American Journal of Psychology, 54, 21-37.

Holmes, O. W. (1859). Atlantic Monthly, 3, 738-748.

Ittelson, W. H. (1952). The Ames demonstrations in perception. Princeton, NJ: Princeton University Press.

ItTELSON, W. H. (1960). Visual space perception. New York: SpringerVerlag.

Ittelson, W. H. (1970). Perception of the large-scale environment. Transactions of the New York Academy of Science, 32, 807-815.

ITTELSON, W. H. (ED.) (1973). Environment and cognition. New York: Seminar Press.

KENNEDY, J. M. (1974). A psychology of picture perception. San Francisco: Jossey-Bass.

KoEnderink, J. J., VAn Doorn, A. J., \& KapPers, A. M. (1994). On socalled paradoxical monocular stereoscopy. Perception, 23, 583-594.

Kubovy, M. (1986). The psychology of perspective and renaissance art. New York: Cambridge University Press.

LEONARDO DA VINCI (1970). The notebooks of Leonardo da Vinci (Vol. 1, J. P. Richter, Ed. \& Trans.). New York: Dover. (Corrected reprint of 1883 transl.)

LEVINSON, J. (1993). Extending art historically. Journal of Aesthetics \& Art Criticism, 51, 411-423.

LiU, C. H., \& KenNedy, J. M. (1994). Symbolic forms can be mnemonics for recall. Psychonomic Bulletin \& Review, 4, 494-498.

MarR, D. (1982). Vision. San Francisco: W. H. Freeman.

Nicholls, A. L., \& KenNedY, J. M. (1993). Angular subtense effects on perception of polar and parallel projections of cubes. Perception, \& Psychophysics, 54, 763-772.

Nye, R., Thomas, G. V., \& Robinson, E. (1995). Children's understanding about pictures. In C. Lange-Kuttner \& G. V. Thomas (Eds.), Drawing and looking (pp. 123-134). New York: Harvester Wheatsheaf.

O'KeEFE, J., \& NADEL, L. (1978). The hippocampus as a cognitive map. Oxford: Oxford University Press, Clarendon Press.

Perceptual organization and obJect ReCOGNITION [Special issues]. (1994). Perception (1994), 23 (4-5).

Peterson, M. (1986). Illusory concomitant motion in ambiguous stereograms: Evidence for nonstimulus contributions to perceptual organization. Journal of Experimental Psychology: Human Perception \& Performance, 12, 50-60.

Petroski, H. (1993). The evolution of useful things. New York: Knopf. PirenNe, M. H. (1970). Optics painting and photography. Cambridge: Cambridge University Press.

Pirenne, M. H. (1975). Vision and art. In E. C. Carterette \& M. P. Friedman (Eds.), Handbook of perception (Vol. 5, pp. 434-490). New York: Academic Press. 
Polanyi, M. (1970). Foreword. In M. H. Pirenne, Optics painting and photography (pp. xv-xix). Cambridge: Cambridge University Press.

RoGERs, S. (1995). Perceiving pictorial space. In W. Epstein \& S. Rogers (Eds.), Perception of space and motion (pp. 119-163). New York: Academic Press.

Rosenblum, L. D., Saldana, H., \& Carello, C. (1993). Dynamica constraints on pictorial action lines. Journal of Experimental Psychology: Human Perception \& Performance, 19, 381-396.

Roskill, M., \& CARRIER, C. (1983). Truth and falsehood in visual images. Amherst: University of Massachusetts Press.

Schlosberg, H. (1941). Stereoscopic depth from single pictures American Journal of Psychology, 54, 601-605.

SEDGWICK, H. A. (1991). The effects of viewpoint on the virtual space of pictures. In S. R. Ellis, M. K. Kaiser, \& A. J. Grunwald (Eds.), Pictorial communication in virtual and real environments (pp. 460479). New York: Taylor \& Francis.

SedGwick, H. A., \& Nicholls, A. L. (1993). Cross talk between the pictured surface and the pictured scene: Effects on perceived shape. Perception, 22(Suppl.), 109

Shepard, R. N., \& METZler, J. (1971, February 19). Mental rotation of three-dimensional objects. Science, 171, 701-703.

SмITH, P. C., \& SMITH, O. W. (1961). Ball throwing responses to photographically portrayed targets. Journal of Experimental Psychol ogy, 62, 223-233.
Stevens, P. S. (1974). Patterns in nature. Boston: Little, Brown. STOFFREGEN, T. A. (1993). "Natural", "real", and the use of non-physical displays in perception-action research. ISEP Newsletter, 6, 4-9.

TUFTE, E. R. (1983). The visual display of quantitative information. Cheshire, CT: Graphics Press.

TUFTE, E. R. (1990). Envisioning information. Cheshire, CT: Graphics Press.

TVERSKY, B. (1995). Cognitive origins of graphic production. In F. T Marchese (Ed.), Understanding images: Finding meaning in digital imagery (pp. 29-53). New York: Springer-Verlag.

WADE, N., \& SWANSTON, M. (1991). Visual perception. London: Routledge.

WARrEN, W. H. (1984). Perceiving affordances: Visual guidance in stair climbing. Journal of Experimental Psychology: Human Perception \& Performance, 10, 683-703.

Wasserman, E. A. (1993). Picture perception: A bird's-eye view. Current Directions in Psychological Science, 2, 184-189.

Wasserman, E. A. (1995). The conceptual ability of pigeons. American Scientist, 83, 246-255.

WeYL, H. (1952). Symmetry. Princeton, NJ: Princeton University Press.

WiLlats, J. (1990). The draughtsman's contract: How an artist creates an image. In H. Barlow, C. Blakemore, \& M. Weston-Smith (Eds.), Images and understanding (pp. 235-254). Cambridge: Cambridge University Press.

\section{APPENDIX}

Contrasts Between the Visual Perception of the Real World and of Markings

\begin{tabular}{|c|c|c|}
\hline Category & Real World & Marking \\
\hline Perceiver & All organisms with visual systems & Humans \\
\hline External source & $\begin{array}{l}\text { Three-dimensional objects, spatial layouts and } \\
\text { events in the world }\end{array}$ & $\begin{array}{l}\text { "Two-dimensional" human expressive, communicative } \\
\text { artifacts }\end{array}$ \\
\hline Visual information & $\begin{array}{l}\text { Varied, open-ended, incompletely defined, } \\
\text { acquired through exploration of multiple sources }\end{array}$ & $\begin{array}{l}\text { Single, fixed, fully defined, independent of real- } \\
\text { world source }\end{array}$ \\
\hline Process & Selective, convergent, closed-ended & Generative, divergent, open-ended \\
\hline Outcome & Unique, fully determined & Indeterminate, tentative, on-going \\
\hline Content & $\begin{array}{l}\text { "Existence"; relevant aspects of the world; } \\
\text { objects, spatial layouts and events of the external } \\
\text { source; "affordances" }\end{array}$ & $\begin{array}{l}\text { "Affectance"; affective, cognitive, and imaginal } \\
\text { content attributed to the marking }\end{array}$ \\
\hline Correctness & $\begin{array}{l}\text { Agreement with external, three-dimensional } \\
\text { world; effective action the criterion for and the } \\
\text { test of correctness }\end{array}$ & $\begin{array}{l}\text { Realization of the expressive and communicative } \\
\text { intent of the maker of the marking tempered by } \\
\text { current social usage; no principled test of correctness }\end{array}$ \\
\hline Action & Action in the immediately present world & $\begin{array}{l}\text { Future action with respect to a world not immediately } \\
\text { present; creation of new markings; "contemplation" }\end{array}$ \\
\hline
\end{tabular}

